\title{
Mapeamento arqueológico e pedológico no Vale do Rio Capivari, Estado de Santa Catarina
}

Raul Viana Novasco ${ }^{1}$

\begin{abstract}
RESUMO: A região sul catarinense oferece uma diversidade ambiental que há milênios vêm possibilitando ao homem diferentes formas de aproveitamento do meio. Essa região é composta por áreas de encostas da Serra Geral e uma planície litorânea, ambos os compartimentos, cobertos por floresta ombrófila densa. Essa configuração vegetal está relacionada aos tipos de solo que recobrem essa região, uma vez que o solo é o responsável pela nutrição das plantas, sejam elas cultivadas ou espontâneas, influenciando muito diretamente na configuração ambiental de determinados espaços. Foi pensando nisso que nos propusemos a desenvolver esse projeto, cujo principal objetivo é o de realizar o cruzamento de dados pedológicos e arqueológicos, a fim de encontrar relações entre a configuração pedológica da região da encosta sul catarinense e as ocupações empreendidas no mesmo espaço durante o período pré-colonial.
\end{abstract}

PALAVRAS-CHAVE: Arqueologia pré-colonial; Pedologia; Mapeamento arqueológico.

ABSTRACT: The southern Santa Catarina offers a diverse environment for millennia that have enabled man to different forms of exploitation of the environment. This region consists of areas of slopes of the Serra Geral and a coastal plain, both compartments, covered by dense rain forest. This vegetation is related to soil types that cover this region, since the soil is responsible for the nutrition of plants, either cultivated or spontaneous, directly influencing the configuration of the local environment. Thinking about what we set out to develop this project, whose main objective is to achieve cross-pedological and archaeological data, in order to find relationships between configuration pedological of the south slope of

\footnotetext{
${ }^{1}$ Graduado em História pela Universidade do Sul de Santa Catarina (U n i s u I) , B r a s i I ; possui experiência em Arqueologia, Topografia e Geoprocessamento desde 2007. Atualmente está cursando mestrado em História, com concentração em Arqueologia na Universidade do Vale do Rio dos Sinos (Unisinos), Brasil. Integra, também, a equipe técnica da empresa de consultoria Espaço Serviços Arqueológicos, onde atua como arqueólogo, desenvolvendo atividades de campo e de gabinete.
} 
Santa Catarina and occupations undertaken in the same area during the pre-colonial period.

KEY-WORDS: Pre-colonial archaeology; Pedology; Archaeological survey.

\section{Introdução}

A região sul catarinense oferece uma diversidade ambiental que há milênios vêm possibilitando ao homem diferentes formas de aproveitamento do meio. Nessa região temos áreas de encostas da Serra Geral e uma planície litorânea, ambos os compartimentos, cobertos por mata atlântica.

Mesmo tendo um grande interesse em trabalhar esse ambiente abordando os seus mais diversos elementos formadores, este estudo foi realizado com o intuito de estabelecer relações entre a ocupação pré-colonial e os tipos de solo que recobrem essa região, uma vez que o solo é o responsável pela nutrição das vegetações, sejam elas cultivadas ou espontâneas, influenciando muito diretamente na configuração do ambiente (VIEIRA, 1975).

No Manual Técnico de Pedologia elaborado pelo IBGE (2007), conceitua-se o solo como a coletividade de indivíduos naturais na superfície da terra, que pode ser modificado ou constituído através da ação antrópica, contendo matéria orgânica viva e servindo à sustentação de plantas ao ar livre.

Já a EMBRAPA (2006), caracteriza o solo como uma coleção de corpos naturais, constituídos por partes sólidas, líquidas e gasosas, tridimensionais, dinâmicos, formados por materiais minerais e orgânicos que ocupam a maior parte do manto superficial da Terra. Contém ainda, matéria viva e podem ser vegetados na natureza onde ocorrem, sendo também passíveis de modificações resultantes de ações antrópicas.

Em síntese, podemos dizer que o solo consiste na união de matéria orgânica decomposta e de materiais inorgânicos (minerais e rochas) não consolidados, que forma uma camada que recobre a 
maior parte da superfície terrestre, sendo esta, responsável pela nutrição natural dos vegetais.

Estudos mostram que os solos diferem regionalmente devido a diferenças em materiais de origem, condições bioclimáticas e idade, o que acaba acarretando variações em sua composição mineralógica, granulometria, profundidade, riqueza em nutrientes, capacidade de retenção de água, porosidade, entre outros (RESENDE, 1988).

As particularidades apresentadas pelo solo de diferentes regiões, tornam possível a existência de diferentes meios bióticos e abióticos, que influenciam diretamente na forma como tal ambiente será ocupado e aproveitado pelo homem que, em qualquer época, ao se estabelecer em um lugar, passa a manter, através de suas atividades, uma relação estreita com o ambiente, onde passa a interferir nos elementos naturais disponíveis.

A área escolhida para a realização deste trabalho está situada no município de São Martinho, mais precisamente na localidade de Salto de Cima, vale do Rio Capivari, onde, até o presente momento, através de pesquisas anteriormente realizadas, foram identificados sítios nos quais verifica-se a presença de vestígios de antigas ocupações empreendidas por grupos caçadorescoletores e horticultores Guarani (EBLE e REIS, 1976; DEMASI, 2004; FARIAS, 2005).

O município de São Martinho está situado dentro do Cinturão Dom Feliciano que é dominado por associações de rochas graníticas dispostas em uma faixa de direção NE que se estende de Santa Catarina ao Uruguai, designada Batólito Pelotas no escudo sul-rio-grandense, Batólito Florianópolis no escudo catarinense e Batólito Aiguá no escudo uruguaio (BITENCOURT, 2008).

O Batólito Florianópolis, o único presente na nossa área de interesse, é composto pela Suíte Plutono-Vulcânica Cambirela, pela Suíte Intrusiva Pedras Grandes e pelo Complexo Granito-Gnáissico. No entanto, das três unidades que compõem o Batólito Florianópolis, somente a Suíte Intrusiva Pedras Grandes e o 
Complexo Granito-Gnáissico estão presentes no contexto geológico do município de São Martinho.

Toda a área é recoberta por Floresta Ombrófila Densa, cuja fisionomia é a de um conjunto denso de árvores, arvoretas, arbustos e ervas, emaranhados por cipós e outros tipo de vegetais. Tais formações apresentam uma enorme biodiversidade com muitas espécies endêmicas, tais como o guaramirim, a perobavermelha, o cedro o pau-d'óleo, a figueira e muitas outras (SANTA CATARINA, 2008).

Pedologicamente, a nossa área de estudo é composta basicamente por Argissolos Vermelhos Alumínicos e Cambissos Húmicos Alumínicos. Estas classes de solos possuem diferenciações quanto à fase de relevo em que ocorrem, bem como quanto a algumas características morfológicas, como textura, atividade de argila, tipo de horizonte $A$ e características físico-químicas. Este fato está bastante relacionado ao material de origem e respectiva posição na paisagem (SANTA CATARINA, 1998).

\section{Os trabalhos de campo}

Durante os trabalhos de campo, duas metas foram estabelecidas: recadastrar e mapear novos sítios, e escavar perfis que nos permitissem fazer uma análise pedológica das áreas onde os sítios encontram-se implantados.

Para a realização dos recadastramentos dos sítios arqueológicos já mapeados em trabalhos anteriores utilizamos uma metodologia que consiste na busca assistemática dos sítios, na qual nos valemos das informações contidas nos cadastros anteriores para chegar até os sítios em questão. Realizamos, também, entrevistas com os moradores da região, a fim de coletar informações que nos levassem a outros sítios arqueológicos ainda não mapeados anteriormente.

Em concomitância com o trabalho de recadastramento dos sítios arqueológicos, escavamos perfis que nos possibilitaram 
verificar a configuração do solo das áreas nas quais os sítios encontram-se implantados. Os perfis escavados possuíam, em média, 1,5 metros de profundidade por 1 metro de largura. A profundidade arbitrada possui tal metragem devido ao fato de que os solos da região ainda estão em formação (cambissolo em sua maioria), logo os processos pedogênicos de alta atividade estão presentes nos primeiros 70 centímetros, salvas as exceções.

A classificação de solos em campo inicia-se na observação dos horizontes que compõem o corpo do rególito. Para realizar esse estudo abrimos trincheiras e retificamos alguns perfis em potencial, uma vez que estes meios permitem o melhor exame das características morfológicas do solo. A descrição morfológica foi feita tendo por base a ficha de descrição e as normas contidas no Manual de Pedologia do IBGE (2007), e após separar os horizontes levando em consideração as variações de cor, textura, estrutura, cerosidade, consistência e transição de horizontes, realizamos a coleta de amostras de solo de cada horizonte, as quais foram acondicionadas em sacos plásticos, sendo devidamente etiquetadas conforme suas especificações para serem encaminhadas ao laboratório, onde passaram por uma secagem para serem novamente analisados segundo a mesma ficha de descrição.

\section{Resultados}

Através do trabalho de recadastramento e de mapeamento que realizamos, foi possível identificar, em uma área relativamente pequena, sítios de filiações culturais diferentes, o que denuncia um processo de reocupação e/ou reaproveitamento do ambiente por grupos distintos que ali estiveram, também, em momentos distintos.

Foram identificados dentro da comunidade do Salto de Cima - em um raio de um quilômetro - dois sítios arqueológicos filiados à subtradição arqueológica Guarani e três sítios com vestígios de grupos caçadores-coletores portadores da tradição 
tecnológica Umbu. Todos os sítios estão muito próximos ao rio, que nesse caso, apresenta-se como o provável elemento central da ocupação pré-colonial naquela área. A seguir seguem a descrição dos sítios bem como os resultados das análises pedológicas realizadas.

\section{SC - São Martinho - 02}

Sítio cadastrado por Marco Aurélio Nadal De Masi, vinculado à subtradição Guarani, localizado sob as coordenadas UTM 22J 699520/6886570, sobre uma várzea às margens do Rio Capivari. Na sua superfície e na subsuperfície é possível verificar a existência de fragmentos de cerâmica e concentração de carvão.

A área onde está implantado o referido sítio se trata de um depósito aluvial que se formou através de inundações seqüenciais do Rio Capivari. Através de um perfil de 1,5 metros de profundidade aberto nas imediações do sítio foi possível identificar esse processo de deposição de sedimento quartzoso, no qual alguns dos horizontes, principalmente o $\mathrm{A}$, apresenta vestígios de atividades antrópicas empreendidas tanto pelos grupos précoloniais, quanto por agricultores contemporâneos.

Logo abaixo do horizonte $A$, identificamos o horizonte $C B$ de caráter flúvico, composto por material mineral quartzoso e pouco acúmulo de argila. Apresenta estrutura granular e granulometria bastante fina. É seguido pelo horizonte $\mathrm{Cg}$, composto por material mineral quartzoso de granulometria fina e com coloração amarronzada, em meio ao qual foram encontrados fragmentos de carvão. Em ambos os horizontes $\mathrm{Cg}$ foram identificamos vestígios vegetais em decomposição ou carbonizados, o que indica que os mesmos se tratam de paleossolos que sofreram soterramento devido a eventuais alagamentos.

Já o horizonte $\mathrm{Cr}$, estabelecido entre os dois horizontes $\mathrm{Cg}$, compõe-se por material mineral quartzoso menos alterado. Apresenta coloração mais amarelada e granulometria intermediária, muito características de sedimentos de deposição aluvial. 
Por fim, tem-se o horizonte $\mathrm{C}$, composto basicamente por sedimento quartzoso de baixa alteração, granulometria bastante grosseira e sem presença de material orgânico. Da mesma forma que o horizonte $\mathrm{Cr}$, possui características de material de deposição aluvial.

As informações obtidas através desse perfil nos levaram a caracterizar o solo daquela área como neossolo flúvico psamítico antrópico. Neossolo por se tratar de um depósito de sedimento quartzoso pouco evoluído; Flúvico por se tratar de um depósito sedimentar resultante de cheias e inundações flúvicas; Psamítico por ter apresentado textura arenosa em todos os horizontes; e Antrópico por apresentar alta atividade antrópica no horizonte A.

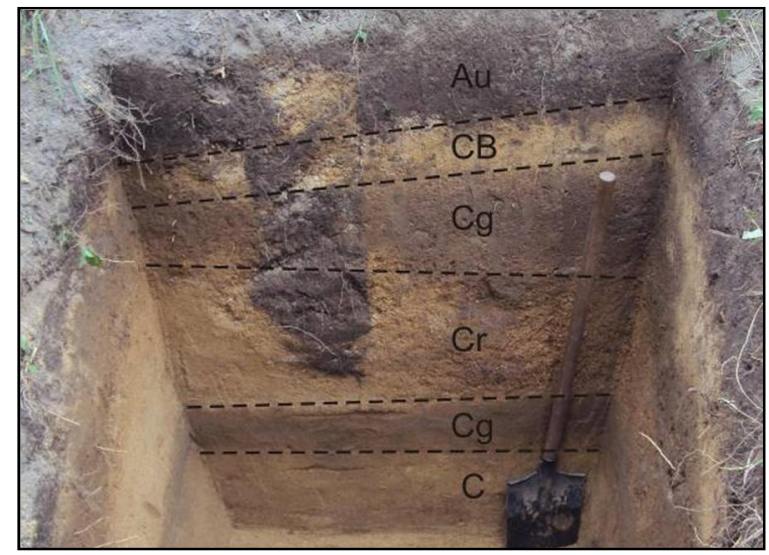

Figura 01

Perfil de NEOSSOLO FLÚVICO Psamítico antrópico

SC - São Martinho - 03

Sítio lítico com presença de lascas em quartzo, características da tradição tecnológica Umbu, localizado nas coordenadas UTM 22J 699075/6887365, e foi mapeado durante o trabalho de recadastramento dos sítios já identificados. 
O tipo de solo que se diagnosticou na área onde o sítio está inserido corresponde às mesmas características identificadas no sítio SC - São Martinho - 01, com pequenas alterações no que diz respeito a hidratação dos óxidos de alumínio, tornando sua coloração um pouco mais avermelhada.

Através da abertura do perfil evidenciou-se a presença do horizonte $A$ antrópico - que equivale a $50 \%$ do perfil de $100 \mathrm{~cm}$ - e a seguir um horizonte $B$ incipiente, pouco desenvolvido e com maior presença de argila e grãos de rocha matriz.

Portanto, temos um cambissolo húmico alumínico antrópico. Cambissolo por ser um solo pouco desenvolvido constituído por material mineral; Húmico por possuir horizonte $A$ húmico; Alumínico por possuir caráter alumínico no horizonte $\mathrm{B}$; $\mathrm{e}$ Antrópico por apresentar alta atividade antrópica no horizonte $A$.

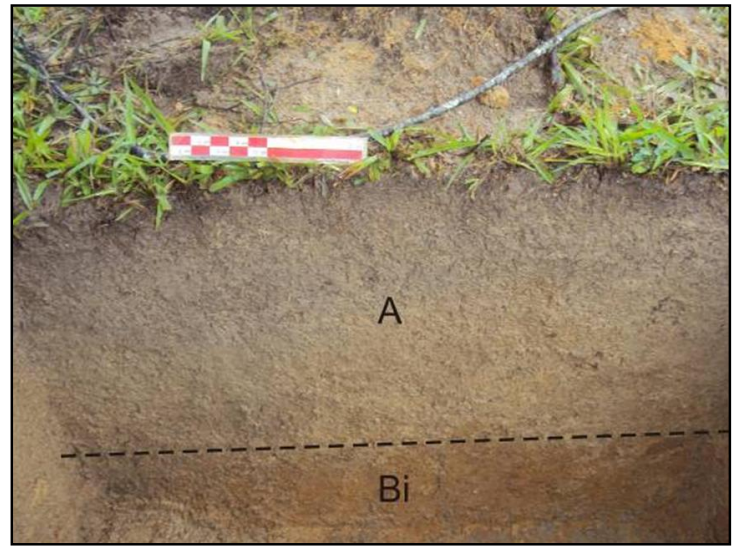

Figura 02

CAMBISSOLO HÚMICO Alumínico antrópico

SC - São Martinho - 04

Sítio lítico com presença de artefatos vinculados a tradição tecnológica Umbu, localizado nas coordenadas UTM 22J 700100/6885775, cadastrado anteriormente por De Masi (2007). 
Está situado em uma suave elevação composta por areia quartzosa característica de depósitos coluviais que se destaca em uma várzea, separando as margens do Rio Capivari dos montes graníticos que formam o vale do Rio Capivari. Associasse aos depósitos de leques aluviais terciário-quartenários, compostos por areias e lamas resultantes da ação de processo de fluxos gravitacionais e aluviais de transporte de material das vertentes.

Através do perfil de 1,3 metros aberto pode-se identificar um horizonte $A$ fraco, pouco desenvolvido, com fraco teor de material orgânico e coloração Hue 25YR 7/6. O horizonte C apresenta um sedimento quartzoso de granulometria intermediária, demonstrando ser pouco afetado pelos processos pedogênicos.

Com isso, através das análises realizadas chegamos a conclusão de que se trata de um cambissolo flúvico alumínico. Cambissolo por ser um solo pouco desenvolvido constituído por material mineral; Flúvico por ter sido formado sob forte influência de sedimento de natureza aluvionar; Alumínico or possuir caráter alumínico no horizonte $\mathrm{C}$.

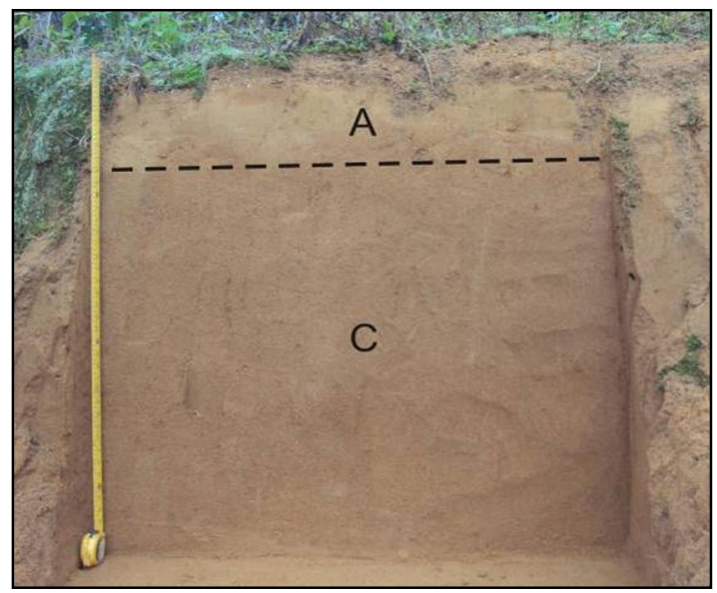

Figura 03

NEOSSOLOS QUARTZARENICOS Órticos 
SC - São Martinho - 05

Sítio lítico com presença de poucas lascas de quartzo, características da tradição tecnológica Umbu, localizado nas coordenadas UTM 22J 699370/6887930, cadastrado anteriormente por De Masi (2007). Está situado em um patamar relativamente plano, que separa uma colina de grande altitude e inclinação das margens do Rio Capivari. Percebe-se no terreno a presença de afloramentos graníticos e a existência de um córrego com pouco volume de água, situado há no máximo 50 metros do sítio.

Para realizar o estudo pedológico da área retificamos um barranco já existente, que provavelmente resulta de processos de erosão natural. Ficou claro em todo o perfil que se trata de um solo ainda muito pouco desenvolvido, o qual é formado em sua maior parte por material mineral quartzoso pouco intemperizado e argila.

O horizonte A apresentou textura arenoargilosa, coloração escura devido à decomposição de material orgânico e presença de raízes de gramíneas e rutáceas. $O$ horizonte $B$ incipiente apresenta maior composição de materiais minerais quartzosos pouco intemperizados em meio à argila mais avermelhada. Apresenta textura mais argilosa do que o horizonte $A$ e sua estrutura toma forma de blocos subangulares. O horizonte $\mathrm{Cr}$ é composto basicamente por rochas inconsolidadas pouco alteradas, sendo seguido pelo horizonte $\mathrm{R}$, no qual encontramos a rocha consolidada.

Dessa forma, caracterizamos esse solo como cambissolo húmico alumínico léptico. Cambissolo por ser um solo pouco desenvolvido constituído por material mineral; Húmico por possuir horizonte A húmico; Alumínico por possuir caráter alumínico no horizonte B; e Léptico por apresentar contato lítico entre $50 \mathrm{~cm}$ e $100 \mathrm{~cm}$ a partir da superfície do solo. 


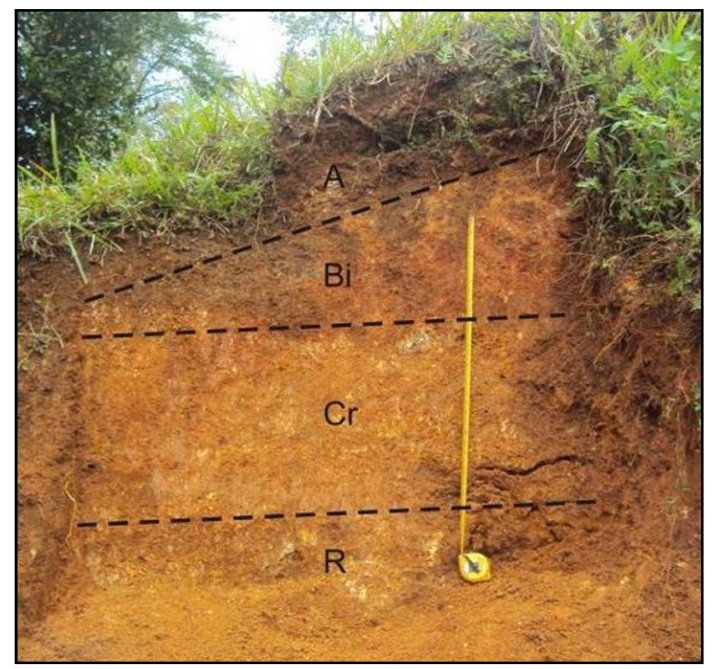

Figura 04

CAMBISSOLO HÚMICO Alumínico léptico

SC - São Martinho - 06

Sítio cerâmico vinculado à subtradição Guarani localizado nas coordenadas UTM 22J 699340/6886590, cadastrado anteriormente por De Masi (2007). Está situado em uma várzea às margens do Rio Capivari característica de depósitos aluviais. Na sua superfície e na subsuperfície é possível verificar a existência de fragmentos de cerâmica e concentração de carvão. Neste sítio não identificamos no perfil a presença de paleossolos, sendo sua composição estratigráfica é mais homogênea, o que denuncia uma menor atividade, tanto de deposição sedimentar, quanto de decomposição de material orgânico.

O horizonte $A$ contém marcas de atividades humanas recentes e pré-coloniais, tais como fragmentos de cerâmica e carvão vegetal. $O$ horizonte $C B$, da mesma forma que no sítio São Marinho - 02 apresenta caráter flúvico, sendo composto por material mineral quartzoso e pouco acúmulo de argila. 
Por conseguinte temos o horizonte $\mathrm{Cr}$, composto por material mineral quartzoso menos alterado. Apresenta coloração mais amarelada e granulometria intermediária, muito características de sedimentos de deposição aluvial. Este é seguido pelo horizonte $C$, também aluvial. É formado basicamente por sedimento quartzoso de baixa alteração, textura arenosa e granulometria grosseira.

Em todo o perfil foi possível identificar marcas de bioturbações causadas por raízes de árvores de médio e grande porte.

Este também se caracterizou como sendo um neossolo flúvico psamítico antrópico. Neossolo por se tratar de um depósito de sedimento quartzoso pouco evoluído; Flúvico por se tratar de um depósito sedimentar resultante de cheias e inundações flúvicas; Psamítico por ter apresentado textura arenosa em todos os horizontes; e Antrópico por apresentar alta atividade antrópica no horizonte $A$.

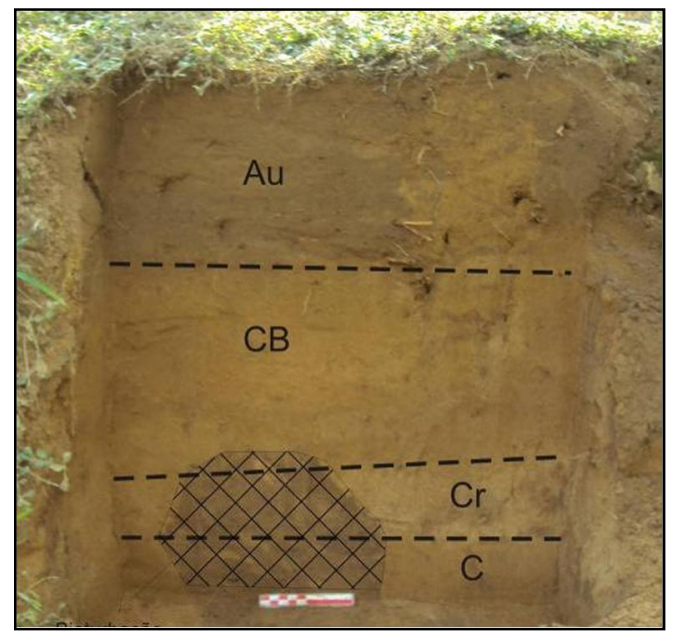

Figura 04

NEOSSOLO FLÚVICO Psamítico antrópico 


\section{Considerações}

Como dito anteriormente, verificamos que os cinco sítios inseridos na área da pesquisa possuem como elemento central o Rio Capivari. Essa forma de implantação, que visa a fácil obtenção de recursos provindos dos rios e córregos, já vem sendo verificada há algum tempo. Pesquisas anteriores já demonstram que os grupos da tradição Umbu assentavam-se em locais com bom potencial extrativo, de onde retiravam o alimento para subsistência e a matéria prima para a produção de artefatos (FARIAS, 2005).

Já os sítios Guarani mapeados não possuem características de locais de aldeamento, uma vez que são sítios relativamente pequenos, compostos por uma única estrutura de combustão de pequenas dimensões situada às margens do rio.

Partindo do pressuposto de que dentro do sistema territorial Guarani existem também áreas de funcionalidades específicas, nas quais são realizadas atividades de captação de recursos das mais variadas naturezas (MILHEIRA, 2008), parece-nos mais adequado propor que os sítios Guarani em questão são resultado desse processo de caça e coleta, sem descartar, no entanto, o uso das terras para pequenos cultivos.

Com as análises pedológicas, diagnosticamos dois tipos de solo, cada qual com suas especificidades dentro de suas ordens. Dois sítios estão implantados em áreas de NEOSSOLOS e os outros três em áreas de CAMBISSOLOS. Os Neossolos são predominantemente Flúvicos, já os Cambissolos são variam entre Húmicos e Flúvicos, ambos de caráter alumínico.

Os tipos de solo identificados derivam do Granito ImaruíCapivari, caracterizado por sua coloração cinza-rosada e pelos abundantes fenoscristais de feldspato alcalino potássico assentados sobre uma matriz quartzo-feldspática (SILVA, 2000).

As análises de campo e de laboratório nos permitiram identificar a presença maciça, e quase única, de quartzo na 
composição dos NEOSSOLOS. Nos CAMBISSOLOS, além do quartzo em seu estado primário, foi possível identificar a presença de argilas silicatadas, formadas a partir do feldspato presente na composição do granito.

O quartzo é um mineral primário que sofre pequenas mudanças na sua composição desde que foi extrusado da lava incandescente, por isso domina as maiores frações do solo. Outros minerais, tais como argilas silicatadas e óxidos de ferro, formam-se a partir da intemperização de materiais menos resistentes à medida que progrediu a formação do solo, por isso são encontrados geralmente nos materiais mais finos, principalmente na argila (BRADY, 1989).

O quartzo $\left(\mathrm{SiO}_{2}\right)$ é o dióxido de silício em estado cristalino. Pode ser encontrado em seu estado primário, restante da cristalização do magma fundido - como o quartzo que ocorre nos granitos - assim como pode ser encontrado em seu estado secundário, procedente da separação do ácido do silício no processo de decomposição dos silicatos, o que justifica ser um dos minerais mais freqüentes na natureza (VIEIRA, 1975).

Assim como as demais espécies minerais do grupo da sílica, o quartzo não é um bom fornecedor de nutrientes aos vegetais, sendo que sua atuação efetiva no desenvolvimento dos mesmos se resume a participar como elemento da composição física dos solos, sendo o mineral predominante na sua fração arenosa. Assim sendo, seja na composição das rochas ou como parte integrante do corpo do solo, o quartzo sempre será o dióxido de silício, elemento inútil para a alimentação das plantas. Isso explica a baixa produtividade agrícola dos Neossolos identificados na área da pesquisa. (VIEIRA, 1975).

Já a argila silicatada encontrada nos Cambissolos, é resultado do processo de alteração física e química dos minerais primários, nesse caso, o feldspato. No processo de alteração física do feldspato são liberados potássio e alumínio, alterando a composição química do mineral, diminuindo a rigidez do cristal, 
iniciando uma mudança básica na cristalografia do mineral original (BRADY, 1989).

$\mathrm{Na}$ decomposição dos feldspatos e dos silicatos em geral, o agente real é o íon de hidrogênio, resultante da quebra da molécula de água e dos ácidos existentes no solo, cuja intensidade é regulada pela temperatura. Para elucidar melhor como se dá tal decomposição, podemos usar como exemplo o feldspato potássico, presente nos Cambissolos identificados na área da pesquisa. Os ânions do grupo silícico, juntamente com o íon de hidrogênio formam o ácido alumínico-silícico não dissociável, que se separa em corpo aparentemente amorfo e instável. A seguir, as alterações atingem esse ácido que se desdobra em suspensão coloidal de hidróxido de alumínio e ácido silícico hidratado. Os metais alcalinos, nesse caso o potássio, unem-se a oxidrilas resultantes da quebra da molécula de água, constituindo produtos solúveis, que por sua vez, são adsorvidos pelos complexos coloidais do solo - aqui a argila silicatada - ou absorvidos diretamente pelos vegetais (VIEIRA, 1975).

O potássio desempenha diversas funções essenciais em relação às plantas. É estimulante de várias enzimas responsáveis por certos processos vegetais, como metabolismo energético, síntese de amido, redução de nitratos e decomposição de açucares. É, ainda, essencial à fotossíntese, assim como à formação do amido e à transferência dos açucares. Em abundancia, tal elemento é importante na formação de grãos, cereais, tubérculos e todas as raízes úteis. Aumenta, também, a resistência das culturas a certas doenças e favorece fortes sistemas radiculares e caulíferos (Brady, 1989).

Assim, podemos perceber que os Cambissolos encontrados na região, mesmo possuindo um teor de alumínio e acidez relativamente altos, proporcionam um bom suporte nutricional para o desenvolvimento de diversos vegetais, sejam eles espontâneos ou cultivados. Isso pode ser percebido através da imensa diversidade de espécies que caracteriza a floresta ombrófila 
densa presente na região e o constante uso das terras por agricultores que lá residem atualmente.

Como resultado da pesquisa, elaboramos o mapa a seguir, no qual cruzamos dados arqueológicos e pedológicos.

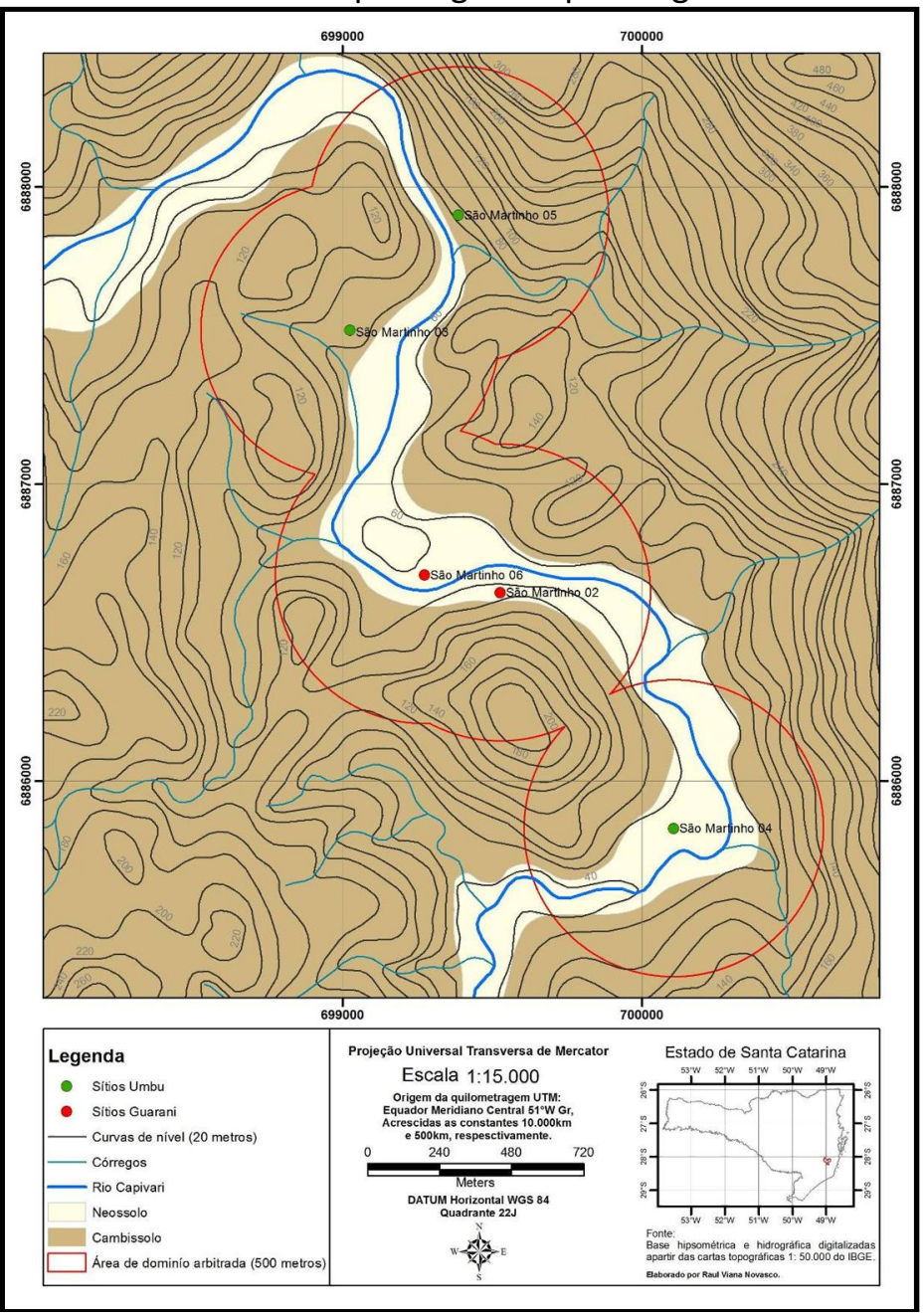

Figura 06

Pedologia da comunidade do Salto de Cima, município de São Martinho 


\section{Conclusões}

A pesquisa desenvolvida teve como motivação inicial comprovar a relação direta entre a escolha dos locais para assentamento dos diferentes grupos que ocuparam a área no período pré-colonial, e os tipos de solo que lá são encontrados.

Identificamos dois sítios relacionados à subtradição Guarani situados em áreas de Neossolos, igualando-se assim ao que se tem no litoral para esse grupo. Os resultados corroboram com nossa hipótese de que esse tipo de solo era buscado pelos grupos da Tradição Tupiguarani, contudo, além de estarmos trabalhando com uma amostra muito pequena, alguns aspectos relacionados à estrutura arqueológica e aos elementos culturais do grupo ainda devem ser considerados.

Acreditamos que os grupos da Tradição Tupiguarani se fixaram naquelas áreas de Neossolo devido a suas características pedológicas, as quais facilitariam o cultivo de plantas já conhecidas pelos mesmos.

Assim como Posey (1986), acreditamos que o conhecimento biológico indígena não se enquadra nas categorias e subdivisões criadas pelas ciências naturais e da terra, classificadas e sistematizadas artificialmente. $O$ seu conhecimento biológico compreende a uma mistura de diversos elementos, tais como as plantas, os animais, a caçada, a horticultura, os espíritos, mitos, energias, etc. Dessa forma, o apego e a busca por um lugar ideal de fixação que proporcione ao grupo o necessário para a sua subsistência, é resultado da embricação entre o mundo natural, simbólico e social, que exige uma abordagem interdisciplinar, através da qual serão respeitados e considerados os aspectos culturais do grupo em questão.

E em se tratando de solo, ainda que o mesmo apareça como um elemento diagnóstico através do qual podemos inferir modelos e propostas para áreas a serem mapeadas, são necessárias escavações de amplas áreas e intensos mapeamentos naquela 
localidade para que se possa identificar algum padrão realmente estabelecido para os sítios vinculados a subtradição Guarani no curso do Rio Capivari. Além disso, deve-se expandir a zona de mapeamento para o interior dos vales, a fim de buscar respostas que elucidem de que forma se deu o processo de migração dos Guarani para essa área de encosta. A identificação de sítios e a obtenção de datas serão capazes de sanar muitas dúvidas ainda existentes no que diz respeito à cronologia Guarani para o sul de Santa Catarina.

Já os sítios encontrados que apresentaram materiais vinculados aos grupos portadores da Tradição Umbu não trouxeram muitas novidades. O padrão de implantação, que compreende a escolha de locais com maior potencial de caça e de coleta, se repete. Dois sítios estão situados em áreas de Cambissolos e um em área de Neossolo.

Partindo do pré-suposto de que estes grupos não praticavam a agricultura, sendo sua subsistência baseada na exploração dos recursos presentes no ambiente, nos arriscamos a dizer que sua relação com o solo era mantida de forma indireta. Como dito anteriormente, o solo é responsável pela nutrição dos vegetais, que por sua vez exerce influência sobre a composição da população faunística. Assim sendo, as variações encontradas nos meios bióticos originais que compõe os diferentes ambientes existentes no planeta, são resultantes das variações no aparato nutricional dos solos que recobrem a parte sólida da Terra. Tendo isso em vista, podemos dizer que a influência que o solo exerce sobre esse grupo diz respeito ao tipo de vegetação espontânea que se desenvolve sobre o mesmo.

Nesse caso, os Cambissolos encontrados na área pesquisada, ainda que sejam ácidos, são boas fontes de potássio, o que possibilita o desenvolvimento de uma vegetação densa e variada que serve de suporte para a sobrevivência de diversas espécies faunísticas, inclusive a espécie humana. No entanto, é pertinente retomar a discussão sobre as escolhas e as variações 
culturais. Não se pode esquecer que a forma como esse ambiente era aproveitado está intimamente relacionada a elementos da cultura imaterial desses grupos.

Tais elementos estão expressos nos mitos e nos rituais, aos quais, muito provavelmente, nunca teremos acesso. 


\section{Referências Bibliográficas}

BITENCOURT, M. F. Estratigrafia do Batólito Florianópolis, Cinturão Dom Feliciano, na Região de Garopaba - Paulo Lopes. In: Revista Pesquisas em Geociências. Porto Alegre, v. 35, n. 1, p. 109-136, 2008.

BRADY. N. C. Natureza e propriedades dos solos. Rio de Janeiro: Ed. Freitas Bastos, 1989.

DE MASI, M. A. N. Projeto de salvamento arqueológico da PCH Rio Capivari. Florianópolis: UNISUL. Relatório final de pesquisa, 2004.

EBLE, A. \& REIS, M. J. Parque Estadual do Tabuleiro: Aspectos culturais e sociais. Florianópolis: FATMA, 1976.

EMPRESA BRASILEIRA DE PESQUISA AGROPECUÁRIA - EMBRAPA. Sistema Brasileiro de Classificação de Solos. Brasília: SPI, 2006.

EPAGRI. Mapa de solos: Unidade de Planejamento Regional Litoral Sul Catarinense. Escala 1:250.000. Florianópolis: EPAGRI, 2002.

FARIAS, D. S. E. Distribuição e padrão de assentamento: propostas para os sítios da Tradição Umbu na encosta de Santa Catarina. Porto Alegre: PUCRS. Tese de Doutorado 2005.

INSTITUTO BRASILEIRO DE GEOGRAFIA E ESTATÍ́STICA - IBGE.

Manual técnico de Pedologia. 2ªed. Rio de Janeiro: IBGE, 2007.

MILHEIRA, R. G. Território e Estratégia de Assentamento Guarani na Planície Sudoeste da Laguna dos Patos e Serra do Sudeste. São Paulo: USP. Dissertação de mestrado, 2008.

POSEY, D. A. Etnobiologia: Teoria e método. In: Suma etnológica brasileira. Petrópolis: Vozes, v. 1, p. 15-25, 1986.

RESENDE, M. Pedologia e fertilidade do solo: interações e aplicações. Brasília. DF: MEC, 1988.

SCHMITZ, P. I. O povoamento indígena do sul do Brasil. In: Maracajá: Pré-história e arqueologia. Tubarão: Editora Unisul, 2005.

SENGIK, E. Uma visão global de solos. Maringá: NUPEL-UEM, 2003. 
SILVA, M. A. S. Programa Levantamentos Geológicos Básicos do Brasil. Criciúma, Folha SH.22-X-B. Estado de Santa Catarina. Escala 1:250.000. Brasília: CPRM, 2000.

VIEIRA, L. S. Manual da ciência do solo. São Paulo: Agronômica Ceres, 1975. 
